\title{
Arazi örtüsü ile meşcere gelişim çağı ve kapalılığı kategorilerindeki zamansal değişimlerin incelenmesi: Karabiga Orman İşletme Şefliği örneği
}

\author{
Sinan Kaptan ${ }^{\text {a,* }}$ (i⿱
}

\begin{abstract}
Özet: Küresel felaketlerin itici gücü olarak kabul edilen arazi kullanımı/örtüsü değişimlerinin incelenmesi ve değerlendirilmesi karar alıcılar, planlamacılar ve yöneticiler için daha sağlıklı ve tutarlı kararların alınmasına önemli katkı sunmaktadır. Özellikle zaman, emek ve maliyetin yüksek olduğu ormancıllk sektöründe yaşanan değişimlerin incelenmesi, raporlanması ve haritalandırılması oldukça önemlidir. Bu çalışmada, Biga Orman İşletme Müdürlüğü Karabiga Orman İşletme Şefliği'nin arazi kullanımı/örtüsünde, orman alanlarında, gelişim çağlarında ve kapalılık sınıflarında yaşanan değişimler için ayrıntılı bir zamansal ve mekânsal değerlendirme yapılmıştır. Çalışmada Orman Genel Müdürlüğ̈̈’nden temin edilen plan ünitesinin 1995 ve 2018 y1lı sayısal meşcere tipleri haritaları kullanılmıştır. Coğrafi Bilgi Sistemleri (CBS) yazılımlarından ArcGIS 10.8 kullanılarak ilgili haritaların öznitelik verilerinde yer alan meşcere tipleri verileri aracılığıyla orman ve orman dışı olmak üzere iki ayrı sınıf altında kategoriler oluşturulmuştur. Orman alanlarında yaşanan değişimlerin ağaç türü, gelişim çağı ve kapalılık sınıfları açısından ele

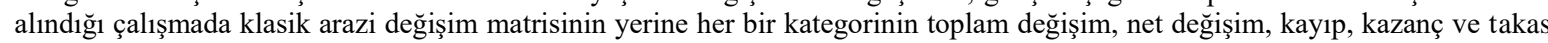
değişim miktarlarını gösteren matris tablo oluşturulmuştur. Bu tablo yardımıyla orman ve orman dışı alanlara ait her bir kategoride yaşanan değişimler ve eğilimler hakkında daha ayrıntılı bilgilere ulaşılmıştır. Çalışma sonuçlarına göre; arazi örtüsünün \%27'sinde, gelişim çağının \%56'sında ve kapalılık sınıfının ise \%55'inde değişim yaşanmıştır. Arazi örtüsü kategorisinde yapraklı orman \%61, ağaçsız orman $\% 30$ ve ziraat $\% 1$ azalırken, ibreli orman \%9 ve yerleşim alanı $\% 20$ artmıştır. 1995-2018 dönemi boyunca, karışık, maki, orman dışı ve özel ağaçlandırma kategorilerindeki değişiklikler sadece net bir değişiklikten oluşurken, diğer kategorilerdeki değişiklikler hem net hem de takas tipi değişikliklerden oluşmuştur.
\end{abstract}

Anahtar kelimeler: Arazi örtüsü değişim, Gelişim çağı, Kapalılık, CBS, Karabiga

\section{Investigation of temporal changes in land cover and in categories of forest development age and crown closure: The case of Karabiga Forest Planning Unit}

\begin{abstract}
The study and evaluation of land use/cover changes that are considered to be the driving force of global disasters contribute significantly to healthier and more consistent decisions for decision makers, planners and managers. Especially in the forestry sector, where time, Labor and cost are high, it is very important to study, report and map changes. In this study, a detailed temporal and spatial assessment was made for changes in land use/cover, forest areas, development stages and crown closure classes of Karabiga Forest Planning Unit of Biga Forest Enterprise. In the study, the forest cover type maps of the forest plan unit obtained from the General Directorate of Forestry in 1995 and 2018 were used. Using ArcGIS 10.8, one of the Geographical Information Systems (GIS) software, categories under two separate classes, forest and non-forest, were created through stand types data included in the attribute data of the relevant maps. In the study in which the changes in forest areas were discussed in terms of tree type, development stage and crown closure classes, a matrix table showing the total change, net change, loss, gain and swap change amounts of each category was created instead of the classical land change matrix. With the help of this table, more detailed information was obtained about the changes and trends in each category of forest and non-forest areas. According to the results of the study; $27 \%$ of the land cover, $56 \%$ of the development stage and $55 \%$ of the crown closure class have changed. In the category of land cover, broad-leaved forest decreased by $61 \%$, treeless forest by $30 \%$ and agricultural by $1 \%$, while coniferous forest increased by $9 \%$ and settlement area by $20 \%$. During the period $1995-2018$, changes in the mixed, maquis, non-forest and special afforestation categories consist of only a net change, while changes in other categories consist of both net and swap changes.

Keywords: Land cover change, Development stage, Crown closure, GIS, Karabiga
\end{abstract}

\section{Giriş}

Arazi kullanımı/arazi örtüsü (LULC) değişikliği, iklim değişikliği, kentsel planlama ve ormancılık alanlarında en iyi bilinen ve en önemli araştırma konularından birisidir (Turner vd., 1994; Watson vd., 2000; Doaemo vd. 2020). Çevresel değişimin ana bileşenlerinden biri olarak kabul edilen LULC değişikliği yerel ve bölgesel düzeyde iklimi, karbonu, suyu ve biyolojik çeşitliliği etkilemektedir (Grimm vd.,
2008; Turner vd., 2007; Yu vd., 2016). Bölgesel ve küresel ölçekte yaşanan LULC değişikliklerinin başlıca nedenlerini orman bozulması, tarım alanı genişletme, küreselleşme ve kentleşme olarak açıklayan pek çok kaynak mevcuttur (Lambin vd., 2001; Vivekananda vd., 2020). Son yıllarda farklı disiplinlerden bilimsel araştırmacılar, arazi kullanım değişikliklerinin sebep ve sonuçlarını daha iyi anlamaya, gelecek yıllar için arazi kullanım değişikliklerinin kapsamını $\begin{array}{lll}\bigotimes & \text { a } & \text { Bartın Üniversitesi, Orman Fakültesi, Orman Mühendisliği, 74100, Bartın } \\ @ & * & \text { Corresponding author (İletişim yazarı): skaptan@ bartin.edu.tr } \\ \checkmark & \text { Received (Geliş tarihi): 26.03.2021, Accepted (Kabul tarihi): 04.05.2021 }\end{array}$
Citation (Atıf): Kaptan, S., 2021. Arazi örtüsü ile meşcere gelişim çağı ve kapalılı̆̆ kategorilerindeki zamansal değişimlerin incelenmesi: Karabiga Orman İşletme Şefliği örneği. Turkish Journal of Forestry, 22(2): $97-$ 104. DOI: $10.18182 /$ tjf.903733 
ve yerini araştırmaya yoğunlaşmışlardır (Verburg vd., 2004; Aksoy ve Kaptan, 2020).

Ormanlar yerel, bölgesel ve küresel ölçekte ekonomik, ekolojik ve sosyokültürel olmak üzere çok çeşitli fonksiyonlara sahiptir. Özellikle son yıllarda etkileri sıklıkla görülen küresel iklim değişiminin yavaşlatılması ve geciktirilmesi konusunda ormanlar hayati derecede öneme sahiptir. Küresel ısınmanın en önemli ana kaynağının sera gazı emisyonları ve özellikle de $\mathrm{CO}_{2}$ emisyonları olduğu kabul edilmektedir (Prada vd., 2020; Wang vd., 2019; Wang vd., 2021). Orman ekosistemleri karbondioksiti fotosentez yoluyla bünyesinde uzun yıllar depolama özelliğine sahiptir (Durkaya vd., 2016). Küresel düzeyde önem arz eden ormanların korunması, iyileştirilmesi, genişletilmesi ve izlenmesi hususu ülkelerin ortak hareket etmesini mecbur kılmıştır (Kaptan vd., 2019). Özellikle küresel karbon bütçesinin dengelenmesi, habitatların korunması, iklim değişikliğinde ormanların rolünün anlaşılması için yaşanan değişimlerin izlenmesi kritik derecede önemlidir (Hayes ve Cohen, 2007).

Dünyada orman alanları ve arazi örtüsünde yaşanan değişimlerin izlenmesi ve değerlendirilmesi çalışmalarında CBS araçları ve uzaktan algılama teknikleri çok yaygın ve etkin şekilde kullanılmaktadır. Ülkemizde CBS teknikleri kullanılarak orman alanlarında yaşanan değişimlerin incelendiği birtakım çalışmalar mevcuttur (Kanja ve Karahalil, 2015; Reis vd., 2016, Bayramoğlu ve Kadığulları, 2017; Kaptan ve Durkaya, 2019; Keten ve Zengin, 2020; Çoban ve Gündoğdu, 2020). Yaşanan değişikliklerin sebep ve sonuçlarını anlamak, arazi kullanım politikalarının etkinliğini değerlendirmek için orman örtüsünün geçmişini gösteren temel verilere ihtiyaç vardır (Kim vd., 2014). Ülkemiz orman alanlarındaki zamansal ve mekânsal değişimlerin incelendiği çalışmaların genelinde meşcere tipleri haritaları kullanılmaktadır. Fakat geçmişe dönük meşcere tipleri haritalarının sayısal olmaması değişim periyotlarının çok kısa kalmasına sebep olmakta, bu da ülkemizdeki çalışmaların 50 yıldan daha geriye gidemediğini göstermektedir (Keten ve Zengin, 2020).

Sürdürülebilir ormancılığın sigortası olarak görülen orman amenajman planlarının temel altlığını oluşturan meşcere tipleri haritaları yersel ve uzaktan algılama metotlarının bir arada kullanılmasını içeren kombine envanter yöntemine göre üretilirler. Bu haritalar orman ve orman dış1 alanlar, meşcerelerin ağaç türü, gelişim çağı ve kapalılığı açısından çeşitli bilgileri içerirler. Dolayısıyla bu haritaların doğruluğu ve güvenirliliği hem planın yapımını, uygulamalarını ve sonuçlarını hem de orman alanlarının zamansal ve mekânsal değişimlerini etkiler. Sürdürülebilir orman yönetimi kapsamında ülkeler, taraf oldukları çeşitli uluslararası anlaşmaların şartlarını yerine getirmek ve ulusal ormancılık amaçlarını gerçekleştirmek için ormancılık politikalarını en doğru şekilde belirlemek zorundadırlar. Düzgün bir ormancılık politikası geliştirmek ve saptanan hedeflere ulaşmak için orman alanlarında yaşanan değişimlerin izlenmesi, haritalanması, raporlanması ve değerlendirilmesinin önemi büyüktür.

Bu çalışmada Çanakkale Orman Bölge Müdürlüğü, Biga Orman İşletme Müdürlüğü'nün Karabiga Orman İşletme Şefliği'nde 1995-2018 arasında yaşanan arazi örtüsü değişiklikleri orman ve orman dışı olarak iki ayrı sınıfta incelenmiştir. Arazi örtüsünde yaşanan değişimler ibreli, yapraklı, karışık, maki, ağaçsız, orman dışı, özel ağaçlandırma, yerleşim, su ve ziraat olmak üzere 10 kategori altında incelenmiştir. Orman alanları sınıfında yaşanan değişimler ise gelişim çağı $(\mathrm{a}, \mathrm{b}, \mathrm{c}, \mathrm{d})$ ve kapalılık sınıfı $(1,2$, 3 kapalı) açısından ayrı ayrı incelendi. Bu çalışmada Türkiye ölçeğinde yapılan benzer çalışmalardan farklı olarak her bir kategori için toplam değişim (net değişim + takas değişim $=$ kayıp + kazanç), net değişim, kayıp, kazanç ve takas değişim miktarları tespit edilmiştir. Bu miktarları hesaplamak için klasik arazi değişim matrislerinden farklı şekilde geliştirilmiş bir matris kullanılmıştır. Klasik arazi değişim çalışmalarından farklı olarak geliştirilmiş matrisin kullanılmasıyla kategorilerin değişimleri hakkında elde edilen bilgiler arazi kullanım değişikliği ve eğilimleri hakkında daha fazla fikir sahibi olunmasına katkı sunabilecektir.

\section{Materyal ve yöntem}

\section{1. Çalışma alanı}

Çanakkale ili Biga ilçesi sınırları içerisinde yer alan çalışma alanı orman idaresi bakımından Çanakkale Orman Bölge Müdürlüğü, Biga Orman İşletme Müdürlüğü, Karabiga Orman İşletme Şefliğine bağlıdır. Çalışma alanı coğrafi konum itibariyle $40^{\circ} 28^{\prime} 30^{\prime \prime}-40^{\circ} 08^{\prime} 51^{\prime \prime}$ kuzey enlemleri ile $26^{\circ} 53^{\prime} 18^{\prime \prime}-27^{\circ} 20^{\prime} 01^{\prime \prime}$ doğu boylamları arasında yer almaktadır (Şekil 1). 2018 yılı meşcere tipleri haritası verilerine göre plan ünitesinin $\% 35$ 'i orman, $\% 65$ 'i orman dışı alandan oluşmaktadır. Genel alanın \%21'i normal (verimli), \%11'i boşluklu ve \%2'si ağaçsız orman alanından oluşurken, \%1'i özel ağaçlandırma sahalarından oluşmaktadır. Genel alanın yarıdan fazlası ziraat alanından (\%57) oluşmaktadır. Çalışma alanının \%35'ini temsil eden ormanların \%15'i ibreli, \%8 yapraklı, \%6'sı karışık türlerden oluşurken genel alanın \%8'i makiliktir. Orman alanlarında yayılış gösteren başlıca ağaç türleri ise Macar Meşesi (Quercus frainetto Ten.), Saçlı Meşe (Quercus cerris L.), Fıstık Çamı Pinus pinea, Kızılçam (Pinus brutia), Sahil Çamı (Pinus pinaster)'dir.
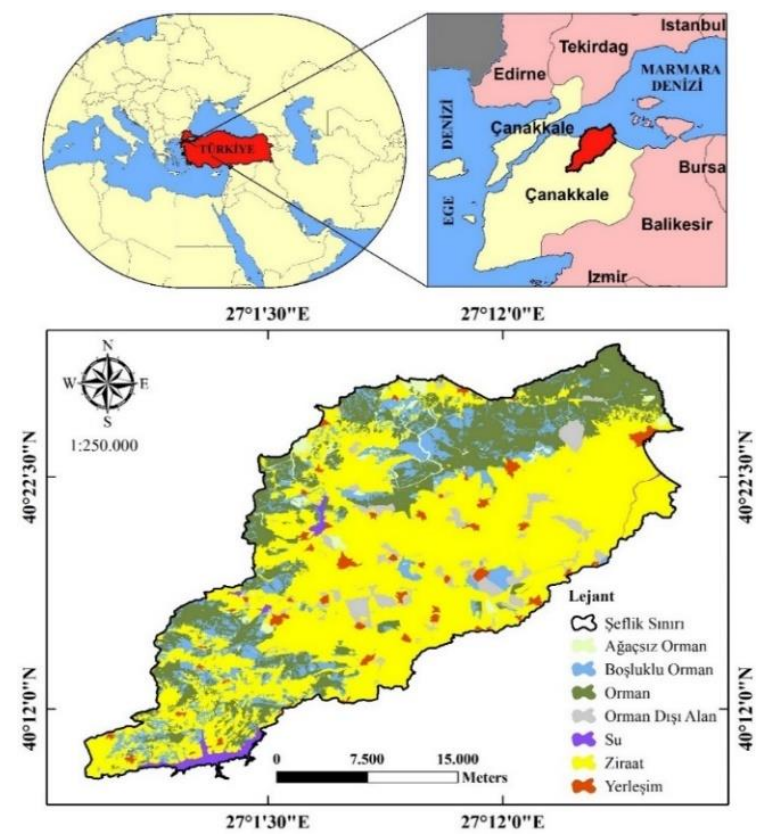

Şekil 1. Çalışma alanına ait lokasyon haritası 
Kuzeyinde Marmara Denizi, batısında Çanakkale İşletme Müdürlüğ̈̈'ne bağlı Lapseki ve Umurbey İşletme Şeflikleri, doğusunda Biga ve Sava İşletme Şeflikleri, güneyinde ise Çan İşletme Müdürlüğü’ne bağlı Karadağ Orman İşletme Şefliği bulunmaktadır. Çalışma alanın ormanları coğrafi olarak Güney Marmara Bölgesi’nde kalmaktadır. İklim olarak ise Alt Akdeniz iklim kuşağı olan Ege iklim kuşağının Ege ardı iklim tipi içinde kalmaktadır. Kışlar mutedil ve yağışlı, yazları ise az yağışlı ve sıcak geçmektedir. Biga ilçesinin kuzeyinde bulunan alanlarda (Değirmencik, Aksaz, Karabiga ve civarları) maki ve frigana formasyonlarının yanında her dem yeşil meşelerden Pırnal Meşesi (Quercus ilex) ve Kermes Meşesi (Quercus coccifera) bu alanların özel doğal bitki örtüsü arasında yer almaktadır (OGM, 2018).

Çalışmada materyal olarak Karabiga Orman İşletme Şefliği'nin orman amenajman planları ve meşcere tipleri haritaları kullanıldı. Kategorilerde yaşanan değişiklikleri tespit etmek için altlık olarak kullanılan sayısal meşcere tipleri haritaları Orman Genel Müdürlüğü Orman İdaresi ve Planlama Dairesi Başkanlı̆̆ı'ndan temin edildi.

\subsection{Yöntem}

Kategoriler arası değişimleri gösteren değişim matrisinin girdilerini oluşturan verileri üretmek amacıyla gerekli olan arazi örtüsü haritalarını üretmek için ArcGIS 10.8 yazılımı kullanılmıştır. İlk olarak meşcere tipi haritalarının projeksiyonları kontrol edilmiş, aynı projeksiyona sahip olmaları sağlanmıştır. Böylece projeksiyon farkından kaynaklanacak üst üste bindirme hataları giderilmiştir. Projeksiyon düzeltme işlemi sonrası her bir haritanın veri tabanındaki "MESCERE" veri alanına göre "Dissolve" (çözme) edilerek kaydedilmiştir. Böylece plan ünitesinin çeşitli yerlerine dağılmış olan, öznitelik tablosunda her biri ayrı ayrı gösterilmiş meşcere tipi (bölmecik) ve alanları bir bütün haline getirilerek tek satırda toplanmıştır. Dissolve edilerek üretilen haritaların veri tabanlarında meşcere tipleri bilgileri kullanılarak arazi örtüsü, ağaç türü, gelişim çağı ve kapalılık sınıfları için yeni veri alanları açılmıştır. Sonrasında veri tabanındaki meşcere bilgileri aracılığıyla her bir kategori için veri girişleri gerçekleştirilmiş ve kaydedilmiştir. Kategori bilgilerini içeren haritalar "Intersect" (kesiştirme) komutu kullanılarak birbiriyle çakıştırılmış ve kaydedilmiştir. Üretilen yeni haritanın veri tabanından kopyalanan veriler ile Excell'de geçiş matrisleri oluşturulmuştur (Çizelge 1).

Geçiş matrisi olarak da adlandırılan bu çapraz sınıflama matrisinin satırları 1. zamandaki $\left(T_{l}\right)$ kategorileri, sütunları ise 2. zamandaki $\left(T_{2}\right)$ kategorileri göstermektedir (Çizelge 1). Kesikli çizgi ile gösterilen hücreler klasik bir geleneksel geçiş matrisidir. Çizelgedeki çapraz girişler $\left(P_{11}, P_{22}, P_{i i}, \ldots\right)$ ilgili kategorinin zaman periyodu arasında değişmeden kalan kısmını (kalıcılık miktarı) ifade ederken, köşegen dışındaki tüm girişler " $i$ ” kategorisinden farklı bir " $j$ ” kategorisine geçiş miktarını göstermektedir (Pontius vd., 2004).

Toplam sütunundaki $P_{i+}$, tüm $i$ satırındaki $P i j$ 'nin toplamı olan $T_{l}$ yılındaki $i$ kategorisine ait alan miktarını göstermektedir. Toplam satırındaki $P_{+j}$, tüm $j$ sütunundaki Pij'nin toplamı olan $T_{2}$ yılındaki $j$ kategorisinin alanını göstermektedir. Çizelgenin kayıp $(L)$ sütunu, $T_{l}$ ile $T_{2}$ zaman aralığında diğer kategorilere dönüşen $i$ kategorisinin toplam arazi miktarını ifade etmektedir. Kazanç $(G)$ satırı ise $T_{l}$ ile $T_{2}$ zaman aralığında $j$ kategorisinin diğer kategorilerden kazandığı toplam arazi miktarını göstermektedir. Kategorinin minimum kazanç ya da kaybının iki katı olan takas değişikliği $\left(S_{j}\right)$, toplam değişim ile net değişiklik arasındaki farka eşittir. Pontius vd. (2004) ve Teferi vd. (2013), arazi kullanımı/arazi örtüsü kategorileri arasında yaşanan eşzamanlı kazanç ve kayıplar olarak ifade edilen takas değişiminin, toplam değişimin açıklanmasında net değişiklikten daha önemli olduğunu ortaya koymuşlardır (Gebremicael vd., 2018). Takas değişim kategorilerin sadece alansal değil konumsal olarak kazanç ya da kayıplarını ifade etmektedir. Örneğin, tüm çalışma alanı içerisinde bir A kategorisinin kazancının ya da kaybının, farklı bir konumdaki B kategorisinin kaybından ya da kazancından kaynaklandığı anlamını içermektedir. Burada kategoriler arasında konumsal olarak yer değiştirme söz konusu olup net değişime bir katkısı yoktur. $\mathrm{Bu}$ çalışma boyunca kullanılan matematiksel gösterimler ve açıklamalar Çizelge 2'de verilmiştir.

Arazi örtüsü değişimleri için ibreli, yapraklı, karışık, maki, ağaçsız, orman dışı, özel ağaçlandırma, yerleşim, su ve ziraat olmak üzere 10; gelişim çağı için B, a, b, c, d olmak üzere 5; kapalılık sınıfı için B, 1, 2, 3 kapalı olmak üzere 4 ayrı kategori oluşturulmuştur (Çizelge 3). Her bir kategori için toplam değişim, net değişimin mutlak değeri, kayıp, kazanç ve takas değişim miktarları belirlenmiştir.

Çizelge 1. Arazi örtüsünün zamansal değişim matrisi (Duan vd., 2021)

\begin{tabular}{|c|c|c|c|c|c|c|c|c|c|c|}
\hline \multirow{2}{*}{$\mathrm{T}_{1}$} & \multirow[b]{2}{*}{ Kategori 1} & \multirow[b]{2}{*}{ Kategori 2} & \multirow[b]{2}{*}{$\ldots$} & \multicolumn{3}{|c|}{$\mathrm{T}_{2}$} & \multirow[b]{2}{*}{$\ldots$} & \multirow[b]{2}{*}{ Kategori J } & \multirow{2}{*}{$\begin{array}{l}\text { Toplam } \\
\mathrm{T}_{1}\end{array}$} & \multirow{2}{*}{$\begin{array}{l}\text { Kayıр } \\
\text { (L) }\end{array}$} \\
\hline & & & & Kategori $i$ & $\ldots$ & Kategori $j$ & & & & \\
\hline Kategori 1 & $P_{11}$ & $P_{12}$ & $\ldots$ & $P_{1 i}$ & $\ldots$ & $P_{l j}$ & $\ldots$ & $P_{l J}$ & $P_{I+}$ & $P_{1+}-P_{11}$ \\
\hline Kategori 2 & $P_{2 I}$ & $P_{22}$ & $\ldots$ & $P_{2 i}$ & $\ldots$ & & $\ldots$ & $P_{24}$ & $P_{2+}$ & $P_{2+}-P_{22}$ \\
\hline$\ldots$ & $\ldots$ & $\ldots$ & $\ldots$ & $\ldots$ & $\ldots$ & $\ldots$ & $\ldots$ & $\ldots$ & $\ldots$ & $\ldots$ \\
\hline Kategori $i$ & $P_{i l}$ & $P_{i 2}$ & $\ldots$ & $\boldsymbol{P}_{i i}$ & $\ldots$ & $P_{i j}$ & $\ldots$ & $P_{i J}$ & $P_{i+}$ & $P_{i+}-P_{i i}$ \\
\hline$\ldots$ & $\ldots$ & $\ldots$ & & $\ldots$ & & $\ldots$ & $\ldots$ & $\ldots$ & $\ldots$ & \\
\hline Kategori $j$ & $P_{j 1}$ & $P_{j 2}$ & $\ldots$ & $P_{j i}$ & $\ldots$ & $\mathbf{P}_{\mathrm{ij}}$ & $\ldots$ & $P_{j J}$ & $P_{j+}$ & $P_{j+}-P_{j j}$ \\
\hline$\ldots$ & $\ldots$ & $\ldots$ & $\ldots$ & $\ldots$ & $\ldots$ & $\ldots$ & $\ldots$ & $\ldots$ & $\ldots$ & $\ldots$ \\
\hline Kategori $J$ & $P_{J I}$ & $P_{J 2}$ & $\ldots$ & $P_{J i}$ & $\ldots$ & $P_{J j}$ & $\ldots$ & $\boldsymbol{P}_{J J}$ & $P_{J+}$ & $P_{J+-} P_{J J}$ \\
\hline Toplam $\mathrm{T}_{2}$ & $P_{+1}$ & $P_{+2}$ & $\ldots$ & $P_{+i}$ & $\ldots$ & $P_{+j}$ & $\ldots$ & $P_{+J}$ & 1 & \\
\hline Kazanç (G) & $P_{+1}-P_{11}$ & $P_{+2}-P_{22}$ & $\ldots$ & $P_{+i}-P_{i i}$ & $\ldots$ & $P_{+j}-P_{j j}$ & $\ldots$ & $P_{+J}-P_{J J}$ & & \\
\hline Net & & & & & & & & & & \\
\hline $\begin{array}{l}\text { Değişim } \\
\left(\mathrm{N}_{\mathrm{j}}\right)\end{array}$ & $G_{l}-L_{l}$ & $G_{2}-L_{2}$ & $\ldots$ & $G_{i}-L_{i}$ & & $G_{j}-L_{j}$ & $\ldots$ & $G_{J}-L_{J}$ & & \\
\hline $\begin{array}{l}\text { Takas }\left(\mathrm{S}_{\mathrm{j}}\right) \\
\text { Toplam }\end{array}$ & $2 \times \min \left(G_{I ;} L_{l}\right)$ & $2 \times \min \left(G_{2 ;} L_{2}\right)$ & $\ldots$ & $2 \times \min \left(G_{i} ; L_{i}\right)$ & & $2 \times \min \left(G_{j ;} L_{j}\right)$ & $\ldots$ & $2 \times \min \left(G_{J ;} L_{J}\right)$ & & \\
\hline $\begin{array}{l}\text { Değişim } \\
\left(C_{j}\right)\end{array}$ & $N_{l}+S_{l}$ & $N_{2}+S_{2}$ & $\ldots$ & $N_{i}+S_{i}$ & & $N_{j}+S_{j}$ & & $N_{J}+S_{J}$ & & \\
\hline
\end{tabular}


Çizelge 2. Çalışmada kullanılan matematiksel gösterimler

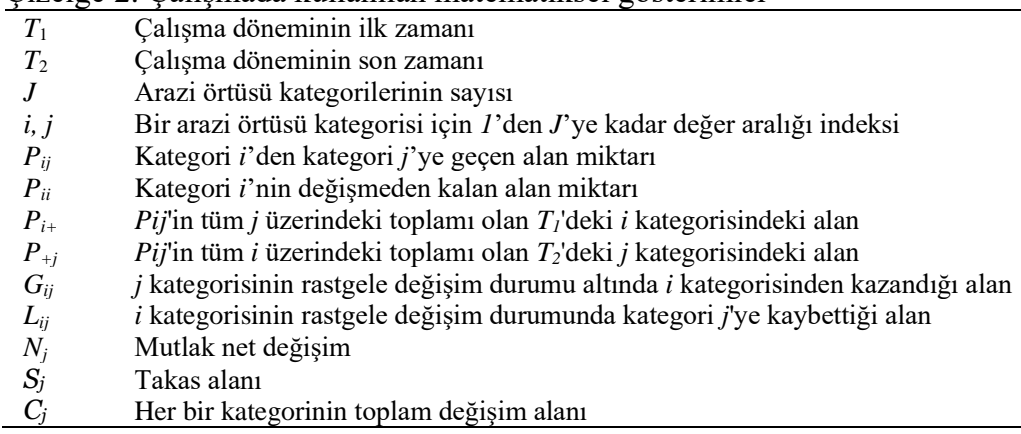

Çizelge 3. Her bir sınıftaki kategorilere ait genel açıklamalar

\begin{tabular}{llll}
\hline Sınıf & Sembol & Değer Aralı̆̆ & Açıklama \\
\hline \multirow{4}{*}{ Gelişim Çağı } & $\mathrm{B}$ & - & Boşluklu kapalı ya da boşaltılmış orman alanı \\
& $\mathrm{a}$ & $\mathrm{d}_{1.30}<8 \mathrm{~cm}$ & Gençlik ve sıklık \\
& $\mathrm{b}$ & $\mathrm{d}_{1.30}=8-19,9 \mathrm{~cm}$ & Srrıklı ve direklik \\
& $\mathrm{c}$ & $\mathrm{d}_{1.30}=20-35,9 \mathrm{~cm}$ & Ince ağaçlık \\
& $\mathrm{d}$ & $\mathrm{d}_{1.30}>36 \mathrm{~cm}$ & Orta ve kalın ağaçlık \\
\hline \multirow{3}{*}{ Kapalılık } & $\mathrm{B}$ & $\% 0-10$ & Boşluklu kapalı \\
& 1 & $\% 11-40$ & Gevşek kapalı \\
& 2 & $\% 41-70$ & Orta kapalı \\
& 3 & $\% 71-100$ & Tam-Normal kapalı \\
\hline
\end{tabular}

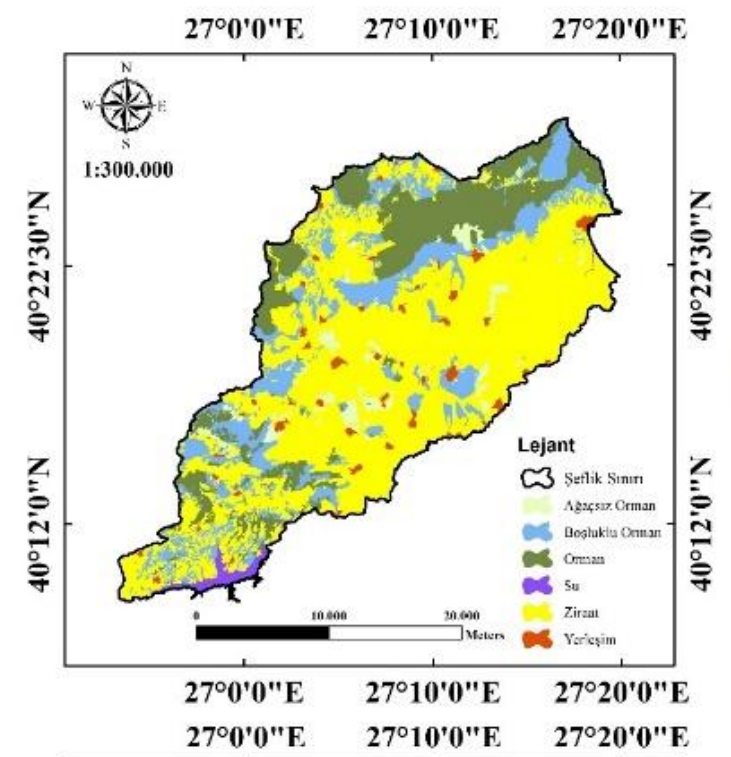

1995 Arazi Kullanımı/Örtüsü (\%)

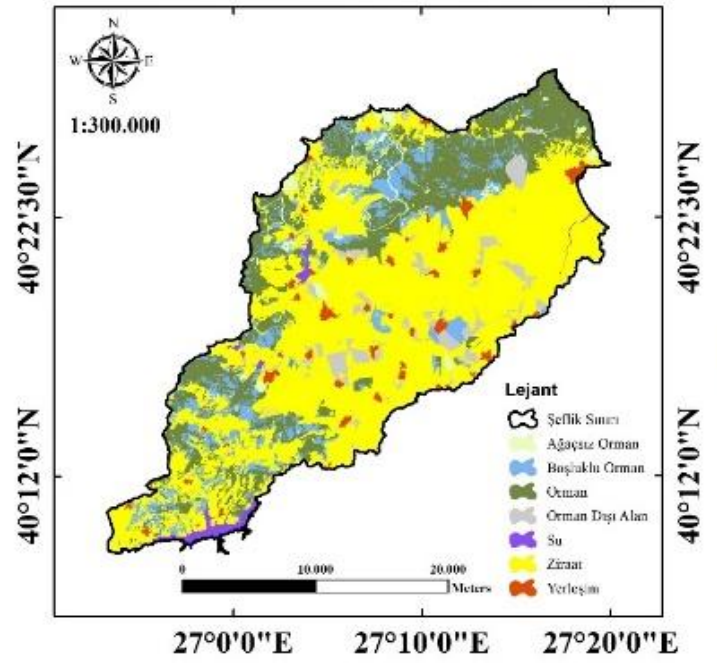

2018 Arazi Kullanımı/Örtüsü (\%)

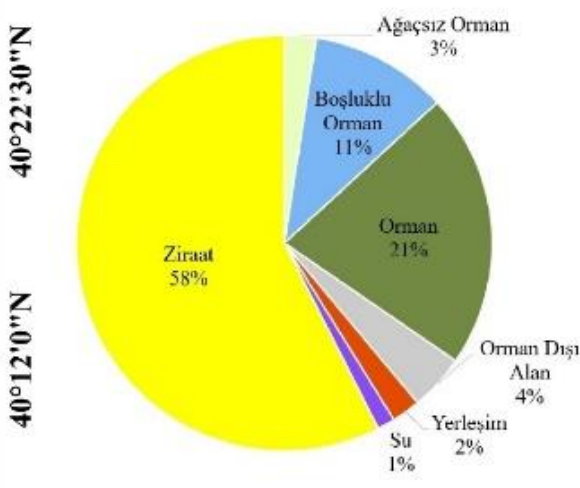

Şekil 2. 1995 ve 2018 yılları arazi kullanımı/örtüsü haritaları 


\section{Bulgular}

\subsection{Arazi kullanımı ve örtüsünde yaşanan değişimler}

Çalışma alanının 2018 sayısal meşcere tipleri haritası verilerine göre genel alan büyüklüğü 63.429,5 ha'dır. Genel alanın \%36'sı orman (22.621,7 ha), \%64'ü orman diş1 alandan (40.807,8 ha) oluşmaktadır (Şekil 2). Çalışma alanının yaklaşık \%27'sinde değişim yaşanırken \%73'ü kalıcılığını korumuştur (Kalıcılık Oranı= Çapraz Girişlerin Toplamı/Toplam Alan*100). 1995-2018 yılları arasinda kategoriler arasında yaşanan arazi örtüsü değişimlerini gösteren Çizelge 4'e göre; karışık orman alanları 3.716 ha ile en fazla kazanç elde eden kategori iken, yapraklı orman 9.792,4 ha ile en fazla kayıp yaşayan kategori olmuştur. Kayıp ile kazanç arasındaki farkı ifade eden net değişim miktarı incelendiğinde; yapraklı orman 23 yıl sonunda $8.255,5$ ha, ağaçsız orman alanı 676,3 ha, ziraat alanı ise 342,7 ha azalmıştır. Karışık orman ile orman dışı alanlarda sırasıyla 3.716 ha ve 2.759 ha net artış yaşanmıştır.

Net değişime göre en yüksek kayıp yaşayan kategori olan yapraklı orman en büyük kayıplarını sırasıyla karışık $(2.964,1$ ha), ibreli (2.628,6 ha) ve ziraat (1.479,8 ha) alanlarına doğru yaşamıştır. Ağaçsız orman alanı 929,9 ha ile orman dışı alana, 528,5 ha ile ziraat alanına, 266,6 ha ile de ibreli ormana en büyük kayıplarını yaşamıştır. Kayıp yaşayan son kategori olan ziraat alanı ise en büyük kayıplarını sırasıyla orman dışı (840,6 ha), yapraklı (529,1 ha) ve ağaçsız orman (420,6 ha) alanına yaşamıştır.

Bir alandaki toplam değişimi anlamak için hem takas hem de net değişiklikler oldukça önemlidir. Çünkü sadece net değişime bağlı kalınarak yapılan analiz, takas değişimlerini hesaba katmakta yetersiz kaldığından toplam değişiklikleri olduğundan az tahmin etmektedir (Pontius vd., 2004; Gebremicael vd., 2018). Karışık orman, maki, orman diş1 alan ve özel ağaçlandırma alanlarında yaşanan değişimler tamamen net değişimden, diğer kategorilerde yaşanan değişimler ise hem net hem de takas değişiminden kaynaklanmaktadır. Çizelge 4'te her bir kategorinin diğer kategorilere kayıplarını gösteren satır değerleri incelendiğinde; karışık orman, maki, orman dışı alan ve özel ağaçlandırma kategorilerinin herhangi kaybının olmadığı, her bir kategoriden elde ettikleri kazançları gösteren sütun değerleri incelendiğinde ise diğer kategorilerden kazanç elde ettiği görülmektedir. Yani bu kategoriler sadece kazanç elde etmiş, takas değişiminin mantığı gereği eş zamanlı olarak kayıp ve kazanç yaşamamıştır. $\mathrm{Bu}$ sebeple kazançları tamamen net değişimden kaynaklıdır. İbreli, ağaçsız, yerleşim, su ve ziraat alanlarının takas değişimi net değişimden büyüktür. Takas değişiminin üstünlüğü, kategoriler arasında karşılıklı kazançlar ve kayıpların yoğun olarak yaşandığını göstermektedir. Diğer kategoriler içerisinde ziraat ve ibrelilerin takas değişim miktarının yüksek olması, arazi kullanım örtüsü kategorileri içerisindeki en dinamik kategoriler olduklarını, çalışma dönemi boyunca takas dinamiğini yaşadıklarını ifade etmektedir.

\subsection{Gelişim çağı sınıfinda yaşanan değişimler}

Çalışma alanının 2018 sayısal meşcere tipleri haritası verilerine göre alanın \%36'sını oluşturan ormanların (22.621,7 ha) \%46's1 “"boşluklu”, \%40'1 “b” çağında, \%13'ü "a" ve \%1'i "c" çağındaki meşcerelerden oluşmaktadır. 1995 yılı meşcere tipleri haritasına göre 2,8 ha olan "d" gelişim çağına 2018 yılında rastlanılmamıştır (Çizelge 5). 1995-2018 yılları arasında gelişim çağları kategorilerinin yaklaşık \%56'sında değişim yaşanırken, \%44'ü sürekliliğini korumuştur.

1995-2018 arasında sınıf içi toplam en büyük değişim 20.239,6 ha ile "boşluklu" orman alanında yaşanmıştır. "Boşluklu" ormanı sırasıyla "a" ve "b" gelişim çağındaki ormanlar takip etmektedir. Kazanç ve kayıp arasındaki farkı gösteren net değişim miktarı açısından en büyük değere ise "b" gelişim çağı sahiptir. Gelişim çağı kategorileri arasında en yüksek kazanç sağlayan kategori olan "b" kazancını 4.640,3 ha ile "a" ve 3.124 ha ile "boşluklu" ormanın kayıplarından sağlamıştır. Bu sonuç alandaki ağaçlandırma ve rehabilitasyon çalışmalarının kısmen de olsa başarılı olduğunun, ormanların çap ve kalite açısından iyileştiğinin bir göstergesi olarak yorumlanabilir. Gelişim çağı kategorilerinde "d" kategorisi hariç gerçekleşen değişimlerin tamamı net ve takas değişimden kaynaklıdır. Takas miktarı "Boşluklu" ve "c" gelişim çağında net değişim miktarından fazladir.

Çizelge 4. 1995-2018 yılı çalışma alanının arazi kullanımı/örtüsü değişim matrisi (ha)

\begin{tabular}{|c|c|c|c|c|c|c|c|c|c|c|c|c|}
\hline \multirow[b]{2}{*}{1995} & \multicolumn{12}{|c|}{2018} \\
\hline & İbreli & Yaprakl & Karışık & Maki & Ağaçsız & $\begin{array}{c}\text { Orman diş1 } \\
\text { alan }\end{array}$ & $\begin{array}{c}\text { Özel } \\
\text { ağaçlandırma }\end{array}$ & Yerleşim & $\mathrm{Su}$ & Ziraat & Toplam & Kayıp $\left(L_{j}\right)$ \\
\hline İbreli & $6.501,5$ & 810,9 & 478,1 & 397,4 & 367,9 & 12,6 & 36,7 & 1,1 & 0,2 & 224,8 & $8.831,2$ & $2.329,7$ \\
\hline Yapraklı & $2.628,6$ & $3.732,1$ & $2.964,1$ & 417,4 & 553,9 & 955,1 & 742,9 & 27,4 & 23,2 & $1.479,8$ & $13.524,5$ & $9.792,4$ \\
\hline Karışık & 0,0 & 0,0 & 0,0 & 0,0 & 0,0 & 0,0 & 0,0 & 0,0 & 0,0 & 0,0 & 0,0 & 0,0 \\
\hline Maki & 0,0 & 0,0 & 0,0 & 0,0 & 0,0 & 0,0 & 0,0 & 0,0 & 0,0 & 0,0 & 0,0 & 0,0 \\
\hline Ağaçsız & 266,6 & 172,4 & 72,0 & 2,3 & 208,9 & 929,9 & 38,7 & 20,7 & 2,6 & 528,5 & $2.242,7$ & $2.033,8$ \\
\hline Orman dişı alan & 0,0 & 0,0 & 0,0 & 0,0 & 0,0 & 0,0 & 0,0 & 0,0 & 0,0 & 0,0 & 0,0 & 0,0 \\
\hline Özel ağaçlandırma & 0,0 & 0,0 & 0,0 & 0,0 & 0,0 & 0,0 & 0,0 & 0,0 & 0,0 & 0,0 & 0,0 & 0,0 \\
\hline Yerleşim & 0,0 & 8,2 & 1,1 & 0,0 & 11,5 & 20,8 & 0,7 & $1.063,5$ & 8,4 & 152,7 & $1.267,0$ & 203,5 \\
\hline $\mathrm{Su}$ & 0,0 & 16,2 & 3,6 & 0,0 & 3,6 & 0,0 & 0,0 & 0,0 & 626,0 & 125,6 & 775,2 & 149,1 \\
\hline Ziraat & 238,3 & 529,1 & 197,1 & 20,5 & 420,6 & 840,6 & 93,2 & 305,6 & 209,3 & $33.934,7$ & $36.788,9$ & $2.854,2$ \\
\hline TOPLAM & $9.635,0$ & $5.269,0$ & $3.716,0$ & 837,6 & $1.566,4$ & $2.759,0$ & 912,2 & $1.418,3$ & 869,7 & $36.446,3$ & $63.429,5$ & \\
\hline Kazanç $(G j)$ & $3.133,5$ & $1.536,8$ & $3.716,0$ & 837,6 & $1.357,5$ & $2.759,0$ & 912,2 & 354,8 & 243,7 & $2.511,5$ & & \\
\hline Net Değişim $(N j)$ & 803,8 & $-8.255,5$ & $3.716,0$ & 837,6 & $-676,3$ & $2.759,0$ & 912,2 & 151,3 & 94,6 & $-342,7$ & & \\
\hline Takas (Sj) & $4.659,4$ & $3.073,6$ & 0,0 & 0,0 & $2.715,0$ & 0,0 & 0,0 & 407,0 & 298,2 & $5.023,0$ & & \\
\hline Toplam Değișim $(C j)$ & $5.463,2$ & $11.329,2$ & $3.716,0$ & 837,6 & $3.391,3$ & $2.759,0$ & 912,2 & 558,3 & 392,8 & $5.365,7$ & & \\
\hline
\end{tabular}




\subsection{Kapalılık sınıfında yaşanan değişimler}

2018 sayısal meşcere tipleri haritası verilerine göre 22.621,7 ha'lık orman alanının \%46'sı "boşluklu", \%11'i “1" kapalı, \%9'u “2” kapalı ve \%34'ü “3” kapalıdır. 1995-2018 yılları arasında en büyük kayıp 6.199 ha ile "1" kapalı, en büyük kazanç ise 5.706,3 ha ile "3" kapalı ormana aittir (Çizelge 6). Kaybı kazancından daha yüksek olan "1" kapalı (4.626,2 ha) ve kazancı kaybından daha fazla olan "3" kapalı (4.105,9 ha) ormanlar net değişim miktarı en yüksek olan kategorilerdir. "1" kapalı ormandan en fazla kayıp 3.102,3 ha ile "3" kapalı ormana doğru gerçekleşmiştir. Kaybı kazancından yüksek olan diğer bir kategori olan "boşluklu" orman kategorisinin 2.587,3 ha'1 "3" kapalı orman tarafindan kazanılmıştır. "Boşluklu" ve "1" kapalı orman kayıplarının “3” kapalı ormanlarda artışa dönüşmesi ormanların yapısında kalitenin arttığını göstermektedir. 1995 yılında 45,8 ha olan "2" kapalı orman alanında 2.082,7 ha'lık artış gerçekleşmiştir. "2" kapalı orman ise en büyük kazancını "1" kapalı orman kaybından (1.134,6 ha) sağlamıştır.

\section{Tartışma ve sonuç}

1995-2018 yılları arasında Karabiga Orman İşletme Şefliği sınırları içerisinde kalan orman alanları ve arazi örtüsünde yaşanan değişimlerin incelendiği bu çalışmada, benzer çalışmalardan farklı olarak her bir kategorinin toplam değişimi, net değişimi, kayıp, kazanç ve takas değişim miktarları belirlenmiştir. Elde edilen sonuçlara göre; orman alanlarında azalmanın olduğu, bu azalmanın da en fazla yapraklı ve ağaçsız orman alanlarındaki azalmalar ile orman dişı alan ve özel ağaçlandırma kategorilerinde yaşanan artışlardan kaynaklandığı görülmüştür. Yapraklı orman alanında gerçekleşen azalma ise büyük bir bölümünün ziraat alanına kaybedilmesinden kaynaklanmaktadır. Her ne kadar ziraat alanı 23 yıllık dönem boyunca yapraklı ormanın kayıplarını kazanç olarak hedeflemiş olsa da diğer kategoriler arasında fazlaca kayıp yaşaması sebebiyle net kayıp yaşayan kategoriler arasında yer almıştır. Yaşanan bu ziraat alanı kayıplarında orman sınırlarının kesinleştirilmesi amacıyla 6831 sayılı Orman Kanunu'na göre yürütülen orman kadastrosunun ve 2/B olarak anılan çalışmaların etkili olduğu düşünülmektedir. Kadığulları vd. (2014), Bozali vd. (2015), Kaptan ve Durkaya, (2019), Kaptan vd. (2019) gibi Türkiye'nin bazı bölgeleri için yapılan çalışmalarda da ziraat alanlarında kayıp yaşandığını gösteren benzer sonuçlara ulaşılmıştır. 2018 yılında ibreli ormanlarda görülen artış büyük oranda yapraklı ormanlardan sağlanan kazanımlara bağlıdır. Ağırlıklı olarak baltalık olarak işletilen meşe ormanlarından oluşan yapraklı ormanlardaki koruya tahvil çalışmalarının ya da muhtemel ağaç türü değişim çalışmaları ile orman içi açıklıkların ağaçlandırmasına yönelik gerçekleştirilen çalışmaların etkileri olabileceğini düşündürmektedir. Keten ve Zengin (2020) ise yaptıkları çalışmada ibreli ormanlarda artış yaşanmasına rağmen yapraklı ormanlarda azalma gerçekleştiğini, bunun sebebi olarak da çalışma alanında gerçekleştirilen ağaçlandırma faaliyetlerinde ağırlıklı olarak ibreli türlerin kullanılmasını göstermişlerdir.

Çizelge 5. 1995-2018 yılları arası çalışma alanı ormanlarının gelişim çağı değişim matrisi (ha)

\begin{tabular}{lllllll}
\multirow{2}{*}{1995} & 2018 & & & & \\
\cline { 2 - 7 } & Boşluklu & $\mathrm{a}$ & $\mathrm{b}$ & $\mathrm{c}$ & $\mathrm{d}$ & Toplam \\
\hline Boşluklu & $7.501,9$ & $1.691,9$ & $3.124,0$ & 70,7 & 0,0 & $12.388,6$ \\
$\mathrm{a}$ & $2.298,7$ & $1.183,5$ & $4.640,3$ & 5,5 & 0,0 & $8.128,0$ \\
$\mathrm{~b}$ & 621,0 & 11,2 & $1.317,8$ & 28,8 & 0,3 & $1.979,2$ \\
$\mathrm{c}$ & 44,6 & 0,0 & 20,3 & 58,5 & 2,5 & 125,9 \\
$\mathrm{~d}$ & 0,0 & 0,0 & 0,0 & 0,0 & 0,0 & 0,0 \\
\hline Toplam & $10.466,2$ & $2.886,6$ & $9.102,5$ & 163,5 & 2,8 & $22.621,7$ \\
Kazanç $(G j)$ & $2.964,3$ & $1.703,2$ & $7.784,7$ & 105,0 & 2,8 & 0,0 \\
Net Değişim $(N j)$ & $-1.922,4$ & $-5.241,4$ & $7.123,4$ & 37,6 & 2,8 & \\
Takas $(S j)$ & $5.928,6$ & $3.406,4$ & $1.322,6$ & 134,8 & 0,0 & \\
Toplam Değişim $(C j)$ & $20.239,6$ & $16.775,8$ & $10.452,2$ & 298,3 & & \\
\hline
\end{tabular}

Çizelge 6. 1995-2018 yılları arası çalışma alanı ormanlarının kapalılık sınıfı değişim matrisi (ha)

\begin{tabular}{|c|c|c|c|c|c|c|}
\hline \multirow{2}{*}{1995} & \multicolumn{6}{|l|}{2018} \\
\hline & Boşluklu & 1 & 2 & 3 & Toplam & Kayıp $\left(L_{j}\right)$ \\
\hline Boşluklu & $7.477,5$ & $1.342,3$ & 621,6 & $2.587,3$ & $12.028,6$ & $4.551,1$ \\
\hline 1 & $1.962,1$ & 868,7 & $1.134,6$ & $3.102,3$ & $7.067,7$ & $6.199,0$ \\
\hline 2 & 9,4 & 2,0 & 17,7 & 16,7 & 45,8 & 28,1 \\
\hline 3 & $1.017,2$ & 228,5 & 354,7 & $1.879,1$ & $3.479,5$ & $1.600,4$ \\
\hline Toplam & $10.466,2$ & $2.441,5$ & $2.128,5$ & $7.585,4$ & $22.621,7$ & \\
\hline Kazanç $(G j)$ & $2.988,8$ & $1.572,8$ & $2.110,8$ & $5.706,3$ & & \\
\hline Net Değişim $(N j)$ & $-1.562,4$ & $-4.626,2$ & $2.082,7$ & $4.105,9$ & & \\
\hline Takas $(S j)$ & $5.977,6$ & $3.145,6$ & 56,2 & $3.200,8$ & & \\
\hline Toplam değișim $(C j)$ & $7.539,9$ & $7.771,8$ & $2.138,9$ & $7.306,7$ & & \\
\hline
\end{tabular}


Her ne kadar zaman içerisinde genel orman alanında azalma gerçekleşmiş olsa da orman alanlarının kalitesinde artış yaşanmıştır. Zaman içerisinde gençlik ve sıklık (a) çağındaki meşcerelerin büyük bölümünün sırıklık ve direklik (b) çağına geçmiş olması silvikültürel açıdan bakım ve koruma çalışmalarının başarıyla yürütüldüğünün bir göstergesidir. Ayrıca gevşek kapalı (1) ormanların büyük bir bölümünün normal kapalı (3) ormana dönüşmesi de bu durumu desteklemektedir. Çizelge 4'te 1993 yılı toplam alan miktarları incelendiğinde; toplam ormanlık alanın yaklaşık $\% 55$ 'i $(13.524,5$ ha) yapraklı ormanlardan, yapraklı ormanların da \%61'i (8.192 ha) meşe türlerinden oluşmaktadır. Değişmeden kalan "b" çağının tamamında meşe türleri hakimdir. Genel olarak incelendiğinde kök ve kütük sürgünlerinden gelen bireyler olması nedeniyle meşeler alandaki aktüel yetişme ortamı koşullarının verimliliği (bonitet) de göz önüne alındığında yeterli düzeyde gelişememiş olabilirler. Doğal olarak bu iki faktörün göstermeleri gereken normal büyüme performanslarının gerisinde kalmalarına neden olduğu düşünülmektedir. Bununla birlikte yöredeki diğer meşe meşcereleri incelendiğinde genel olarak heterojen bir yapının hakim olduğu, yukarıda belirtilen nedenlerle birlikte küresel iklim değişikliğinin sebep olduğu koşullardan dolayı bu duruma hassas olan meşe türlerinde yaşanan büyüme gerilemeleri sınıf değişimini ve gelişim çağları açısından geçişi süre ve kantitatif büyüme karakterleri açısından uzatabilmektedir. Söz konusu durumun nedenlerinin bundan kaynaklı olduğu kuvvetli ihtimalle düşünülmektedir. Amenajman bilimi açısından ise perspektifte alansal olarak yapısal matris değerlendirmelerine dayanan değerlendirmelerin yapıldığg bu durumda "b" çağındaki meşcerelerin alan olarak "c" çağına intikal etmesi gerekirken edemediği, planlama ünitelerinde yeniden değerlendirmelere ve değişimlere yol açtığ görülmektedir. Bu değerlendirmenin altında yatan yine en önemli neden biyolojik ve ekolojik temelli büyüme gecikmelerine bağlı olabilmektedir.

Klasik arazi değişim matrisleri üzerinden yapılan arazi kullanımı ve örtüsü çalışmalarında takas değişimi dikkate alınmadan net değişim üzerinden değerlendirmeler yapıldığ için arazi kullanımı ve örtüsünde yaşanan toplam değişim miktarı olduğundan daha az tahmin edilebilmektedir. Arazi kullanımı ve örtüsünde ve özellikle orman alanları için gerçekleştirilecek zamansal ve mekânsal analizlerde sadece net değişim üzerinden yapılacak değerlendirmelerden kaynaklanan bu sorunu önlemek için kategoriler arasındaki takas değişim miktarının da dikkate alınması ve değerlendirilmesi yararlı olacaktır. Orman alanlarında yaşanan değişimleri üzerinde birden fazla faktörün ortak etkisi söz konusudur. Özellikle ormancılık çalışmalarının şiddeti ve yoğunluğu başta olmak üzere orman içi ve civarında yaşayan insanların ormanlar üzerinde var olan etkilerinin yönü ve şiddetinin yani sosyo-ekonomik koşulların ve nedenlerin bir arada değerlendirilmesinde büyük fayda vardır.

Türkiye ormanlarında yaşanan değişimlerin izlenmesi ve değerlendirilmesinde yaşanan en büyük sorun CBS ortamında analizleri gerçekleştirmek için kullanılacak meşcere tipleri haritalarının (genellikle 2001 ve öncesi) sayısal formatta olmamasıdır. Bu sebeple analizler ya dar bir zaman aralığında ya da küçük bir alanda yürütülmek zorunda kalınmaktadır. Uydu görüntüleri kullanılarak bu sorun kısmen aşılabilse de sağlıklı bir veri elde etmenin yolu uydu görüntüsü sınıflandırma işleminin doğruluğuna ve başarısına bağlıdır. Uydu görüntülerinin denetimli sınıflandırma işleminin başarısının tespitinde meşcere tipleri haritasının kullanıldığı bilinmektedir (Kaptan vd., 2020). Tüm bu ve benzeri gerekçeler eski plan dönemlerine ait meşcere tipleri haritalarının sayısal ortamda bulunmasının önemini göstermektedir. Ayrıca sayısal haritaların öz nitelik verilerinin tüm ülke genelinde standartlara göre düzenlenmesi ve kaydedilmesi de oldukça önemlidir.

\section{Açıklama}

Plan ünitesinin orman amenajman planlarının ve sayısal meşcere tipleri haritalarının temin ve teslimini gerçekleştiren Orman Genel Müdürlügü̆, Orman İdaresi ve Planlama Dairesi Başkanı Sayın Murat ÇEVIRME'ye ve daire başkanlığının değerli personeline sonsuz şükranlarımı sunarım.

\section{Kaynaklar}

Aksoy, H., Kaptan, S., 2020. Simulation of future forest and land use/cover changes (2019-2039) using the cellular automataMarkov model. Geocarto International, (just-accepted), 1-17.

Bayramoğlu, M.M., Kadıŏulları, A.İ., 2017. Analysis of land use change and forestation in response to demographic movement and reduction of forest crime. EURASIA Journal of Mathematics, Science and Technology Education, 14(1): 225238.

Bozali, N., Sivrikaya, F., Akay, A.E., 2015. Use of spatial pattern analysis to assess forest cover changes in the Mediterranean region of Turkey. Journal of Forest Research, 20(4): 365-374.

Çoban, H., Gündoğdu, Ş., 2020. Orman alanlarındaki değişimlerin CBS tabanlı belirlenmesi: Çamsu Orman İşletme Şefliği örneği. Turkish Journal of Forestry, 21(1): 60-69.

Doaemo, W., Mohan, M., Adrah, E., Srinivasan, S., Dalla Corte, A.P., 2020. Exploring forest change spatial patterns in papua new guinea: A pilot study in the Bumbu River Basin. Land, 9(9): 282.

Duan, H., Xie, Y., Du, T., Wang, X., 2021. Random and systematic change analysis in land use change at the category level - A case study on Mu Us area of China. Science of The Total Environment, 777: 145920.

Durkaya, A., Durkaya, B., Kaptan, S., 2016. Biokütle çalışmaları ve gövde odun örneklerinin alınması esasları. Bartın Orman Fakültesi Dergisi, 18(2): 168-174.

Gebremicael, T.G., Mohamed, Y.A., van Der Zaag, P., Hagos, E.Y., 2018. Quantifying longitudinal land use change from land degradation to rehabilitation in the headwaters of Tekeze-Atbara Basin, Ethiopia. Science of the Total Environment, 622: 15811589.

Grimm, N.B., Faeth, S.H., Golubiewski, N.E., Redman, C.L., Wu, J., Bai, X., Briggs, J.M., 2008. Global change and the ecology of cities. Science, 319(5864): 756-760.

Hayes, D.J., Cohen, W.B., 2007. Spatial, spectral and temporal patterns of tropical forest cover change as observed with multiple scales of optical satellite data. Remote Sensing of Environment, 106(1): 1-16.

Kadioğullari, A.İ., Sayin, M.A., Çelịk, D.A., Borucu, S., Çil, B., Bulut, S., 2014. Analysing land cover changes for understanding of forest dynamics using temporal forest management plans. Environmental Monitoring and Assessment, 186(4): 2089-2110.

Kanja, K., Karahalil, U., 2015. Aydoğan Orman İșletme Şefliği orman kaynaklarında meydana gelen zamansal ve konumsal değişimin CBS ve uzaktan algılama yardımıyla ortaya konması. TUFUAB VIII. Teknik Sempozyumu. 21-23 Mayıs, Konya, s. 369-375.

Kaptan, S., Aksoy, H., Durkaya, B., Aksoy, Ş.Ç., 2019. Coğrafi bilgi sistemleri ile arazi örtüsü ve kullanımında yaşanan değişimlerin incelenmesi (Akgöl orman işletme şefliği örneği). $8^{\text {th }}$ International Vocational Schools Symposium, 11-13 Haziran, Sinop, s. 535-542. 
Kaptan, S., Aksoy, H., Durkaya, B., 2020. Estimation of unevenaged forest stand parameters, crown closure and land use/cover using the Landsat 8 OLI satellite image. Geocarto International, $1-18$.

Kaptan, S., Durkaya, A., 2019. Analysing temporal and spatial changes in land cover: the case of Drahna Forest Subdistrict Directorate. Kastamonu Üniversitesi Orman Fakültesi Dergisi, 191: 47-56.

Keten, S., Zengin, H., 2020. Düzce Asar Orman İşletme şefliğinde arazi metriklerindeki zamansal değişimler. Düzce Üniversitesi Orman Fakültesi Ormanc1lık Dergisi, 16(1): 31-48.

Kim, D.H., Sexton, J.O., Noojipady, P., Huang, C., Anand, A., Channan, S., Feng, M., Townshend, J.R., 2014. Global, Landsatbased forest-cover change from 1990 to 2000. Remote Sensing of Environment, 155: 178-193.

Lambin, E.F., Turner, B.L., Geist, H.J., Agbola, S.B., Angelsen, A., Bruce, J.W., Coomes, O.T., Dirzo, R., Fischer, G., Folke, C., George, P.S., Homewood, K., Imbernon, J., Leemans, R., Li, X., Moran, E.F., Mortimore, M., Ramakrishnan, P.S., Richards, J.F., Skånes, H., Steffen, W., Stone, G.D., Svedin, U., Veldkamp, T.A. Vogel, Z., Xu, J., 2001. The causes of land-use and land-cover change: Moving beyond the myths. Global Environmental Change, 11(4): 261-269.

OGM, 2018. Karabiga Ekosistem Tabanlı Fonksiyonel Orman Amenajman Planı (2018-2037). T.C. Tarım ve Orman Bakanlığı, Orman İdaresi ve Planlama Dairesi Başkanlığı, Ankara, $398 \mathrm{~s}$.

Pontius Jr, RG., Shusas, E., McEachern, M., 2004. Detecting important categorical land changes while accounting for persistence. Agriculture, Ecosystems \& Environment, 101(2-3): 251-268.

Prada, M., Prada, I.F., Cristea, M., Popescu, D.E., Bungău, C., Aleya, L., Bungău, C.C., 2020 New solutions to reduce greenhouse gas emissions through energy efficiency of buildings of special importance-Hospitals. Science of the Total Environment, 718: 137446.

Reis, M., Dutal, H., Abız, B., Bolat, N., 2016. Kahramanmaraş ili Göksun ilçesinde arazi kullanımında meydana gelen zamansal değişimin uzaktan algılama teknikleri ve coğrafi bilgi sistemi ile belirlenmesi. Kahramanmaraș Sütçü İmam Üniversitesi Mühendislik Bilimleri Dergisi, 19(2): 35-41.
Teferi, E., Bewket, W., Uhlenbrook, S., Wenninger, J., 2013. Understanding recent land use and land cover dynamics in the source region of the Upper Blue Nile, Ethiopia: Spatially explicit statistical modeling of systematic transitions. Agriculture, Ecosystems \& Environment, 165: 98-117.

Turner, B.L., Lambin, E.F., Reenberg, A., 2007. The emergence of land change science for global environmental change and sustainability. Proceedings of the National Academy of Sciences, 104(52): 20666-20671.

Turner, B., Meyer, W.B., Skole, D.L., 1994. Global land-use/landcover change: Towards an integrated study. Ambio. Stockholm, 23(1): 91-95.

Verburg, P.H., de Nijs, T.C., van Eck, J.R., Visser, H., de Jong, K., 2004. A method to analyse neighbourhood characteristics of land use patterns. Computers, Environment and Urban Systems, 28(6): 667-690.

Vivekananda, G.N., Swathi, R., Sujith, A.V.L.N., 2020. Multitemporal image analysis for LULC classification and change detection. European Journal of Remote Sensing, 1-11.

Wang, C., Zhan, J., Zhang, F., Liu, W., Twumasi-Ankrah, M.J., 2021. Analysis of urban carbon balance based on land use dynamics in the Beijing-Tianjin-Hebei region, China. Journal of Cleaner Production, 281: 125138

Wang, Z., Xue, M., Wang, Y., Song, M., Li, S., Daziano, R.A., Wang, B., Ma, G., Chen, K., Li, X., Zhang, B., 2019. Big data: New tend to sustainable consumption research. Journal of Cleaner Production, 236: 117499.

Watson, R.T., Noble, I.R., Bolin, B., Ravindranath, N.H., Verardo D.J., Dokken, D.J., 2000. Land Use, Land-Use Change and Forestry: A Special Report of The Intergovernmental Panel on Climate Change. Cambridge University Press, United Kingdom.

Yu, W., Zhou, W., Qian, Y., Yan, J., 2016. A new approach for land cover classification and change analysis: Integrating backdating and an object-based method. Remote Sensing of Environment, 177: $37-47$ 